\title{
Surgical treatment of lower limb ischemia in diabetic patients - long-term results
}

\author{
Bekir Inan', Unal Aydin², Murat Ugurlucan², Cemalettin Aydin', Melike Elif Teker ${ }^{1}$
}

${ }^{1}$ Cardiovascular Surgery Department, Bezmi Alem University, Istanbul, Turkey 2Mehmet Akif Ersoy Thoracic and Cardiovascular Surgery Center, Istanbul, Turkey

${ }^{3}$ Anadolu Medical Center Hospital, Cardiovascular Surgery Clinic, Istanbul, Turkey

Submitted: 4 October 2011

Accepted: 26 November 2011

Arch Med Sci 2013; 9, 6: 1078-1082

DOI: 10.5114/aoms.2013.39630

Copyright @ 2013 Termedia \& Banach

\begin{abstract}
Introduction: Lower limb ischemia may cause nonhealing ulcers, infection, amputation and even mortality in diabetic patients. In this study, we review our data of ischemic lower limb revascularization procedures in diabetic patients and present the early, mid- and long-term results.

Material and methods: From March 2004 to September 2008, 83 patients with lower limb ischemia in Fontaine class III and IV underwent distal arterial bypass procedures. Saphenous vein grafts were used for below-knee arterial bypasses in all patients. In 16 (19\%) patients femoropopliteal bypasses were performed with PTFE grafts. Short-term and long-term surgical results were evaluated.

Results: Ulcer recovery was determined in $36 \%$ of patients. Graft patency was $95 \%$ and 1 death (1\%) occurred in short-term follow-up. In long-term followup the total effectiveness rate was $74 \%$. Graft patency was $79 \%$ and 6 deaths (7\%) occurred during the follow-up.

Conclusions: Lower limb ischemia is a serious event in patients with diabetes mellitus. The consequences may include increased mortality and morbidity in this particular patient population. However, distal arterial revascularizations are considerably effective procedures to avoid amputation, to eliminate symptoms, to promote ulcer recovery and to help the patient participate in social life with acceptable short, mid- and long-term follow-up results.
\end{abstract}

Key words: diabetes mellitus, diabetic food, ischemia, distal arterial bypass.

\section{Introduction}

Diabetes mellitus (DM) is a widespread pathology in the world population and the prevalence of diabetes for all age groups was $2.8 \%$ in 2000 and is estimated to be $4.4 \%$ in 2030 . The total number of people with diabetes is projected to rise from 171 million in 2000 to 366 million in 2030. Its complications such as neuropathy, retinopathy, nephropathy and atherosclerosis are the major causes of morbidity and mortality of this multisystemic disease. Peripheral vascular disease in lower extremities varies from asymptomatic to critical limb ischemia in the presence of DM. Vascular disease in diabetic patients provokes ulcers and gangrene, finally leading to amputation or even death. Most authors mention diabetes as an important risk factor in the development of critical and/or chronic limb ischemia and consequent amputation [1]. It is important to perform surgical and medical treatments for diabetic patients with lower limb ischemia [2]. Recovery and increasing the life quality are the targets of these procedures.

\author{
Corresponding author: \\ Unal Aydin MD \\ Mehmet Akif Ersoy \\ Thoracic and Cardiovascular \\ Surgery Clinic \\ Halkali, Istanbul, Turkey \\ Phone: +90 5323507622 \\ Fax: +90 4323122867 \\ E-mail: \\ allosanfan@hotmail.com
}


In this study, we review our data of ischemic lower limb revascularization procedures in diabetic patients and present the early, mid- and longterm results.

\section{Material and methods}

Between March 2004 and September 2008, 931 peripheral vascular bypass procedures were performed at our institution. Among them 83 patients received lower limb surgical revascularization for critical limb ischemia. Demographic data and risk factors are presented in Table I. Exclusion criteria were emergent operations, redo cases, acute thrombosis and distal embolisation.

Mean age of the patients was $58.61 \pm 4.80$ years. Seventy-two of them were males and 11 were females. Hypertension was present in 72 cases (93\%). Incidences of significant atherosclerotic coronary artery disease and congestive heart failure occurred in $18(21 \%)$ and 24 (28\%) patients, respectively. Active smoking was present in 55 (66\%) cases. There was nephropathy in 15 (18\%) patients. Mean glycated haemoglobin $\left(\mathrm{HbA}_{1 \mathrm{c}}\right)$ was measured to be $7.29 \pm 0.45 \%$. According to the Fontaine classification 47 (57\%) patients had class III disease and 36 (43\%) had class IV limb ischemia. Diagnosis modalities were Doppler ultrasonography and angiography. These diagnostic modalities were performed in all patients. The Bollinger scoring system [3] was used to assess the severity of arterial disease. In this system, each arterial segment is assigned a number corresponding with disease severity. The minimum score is 0 , indicating a normal segment; the maximum score is 15 , indicating total occlusion extending for more than half the length of a segment. The results are presented in Table II.

Medical treatment protocols of patients were organized with antiaggregant/anticoagulant, statin

Table I. Demographic data and risk factors

\begin{tabular}{|lc|}
\hline Parameter & Results \\
\hline Age, mean \pm SD & $58.61 \pm 4.80$ \\
\hline Sex (M/F), $n(\%)$ & $72(86) / 11(13)$ \\
\hline Hypertension, $n(\%)$ & $78(93)$ \\
\hline ACAD, $n(\%)$ & $18(21)$ \\
\hline CHF, $n(\%)$ & $24(28)$ \\
\hline DM, $n(\%)$ & $83(100)$ \\
\hline COPD, $n(\%)$ & $14(16)$ \\
\hline Smoking, $n(\%)$ & $55(66)$ \\
\hline Nephropathy, $n(\%)$ & $15(18)$ \\
\hline HbA ${ }_{1 c}$ (mean \pm SD) & $7.29 \pm 0.45$ \\
\hline
\end{tabular}

$A C A D$ - atherosclerotic coronary artery disease, $C H F$ - congestive heart failure, DM - diabetes mellitus, COPD - chronic obstructive pulmonary disease and vasodilator therapies. Blood glucose range was controlled with crystallized insulin. Combined antibiotics according to drug sensitivity testing were used to control infection. Foot wounds were debrided with hydrogen peroxide, $0.9 \% \mathrm{NaCl}$ solution and collagenase pomade. Hyperbaric oxygen therapy was performed in 16 (19\%) patients and iloprost was included in the medical therapy in 18 (21\%) patients. Low molecular weight heparin was administered in preoperative and postoperative periods. Severity of patients' symptoms was evaluated by the ankle-brachial index (ABI). Ankle-brachial index was < 0.3 in 46 (55\%) patients, 0.3-0.5 in 28 (33\%) patients, and $>0.5$ in $9(10 \%)$ patients.

Operations were performed under general anesthesia in 5 (6\%), epidural anesthesia in 52 (62\%) and with regional nerve block in 26 (31\%) patients. A summary of the operations performed on patients is presented in Table III. Autologous saphenous vein grafts were used in all patients for distal bypass procedures. A polytetrafluoroethylene (ePTFE) graft with a diameter of $6 \mathrm{~mm}$ was used in $16(19 \%)$ patients for femoropopliteal bypass procedures. The proximal site of the popliteal artery with adequate flow, diagnosed with angiography and noninvasive studies, was selected for proximal anastomosis. Proximal anastomosis was performed at the distal segment of the femoropopliteal bypass graft (ePTFE) in 16 patients. Inflow anastomoses were performed with 6.0 monofilament suture and outflow anastomoses were performed with 6.0 or 7.0 monofilament suture. A $100 \mathrm{U} / \mathrm{kg}$ of heparin was administered before arterial clamping, and heparin was not reversed after the flow was maintained.

After hospital discharge antithrombotic and antioxidant agents such as acetylsalicylic acid, clopidogrel, cilostazol, and pentoxifylline were used for the treatment and better graft patency.

Table II. Surgical procedures

\begin{tabular}{|lc|}
\hline Procedure & Number (percent) \\
\hline $\begin{array}{l}\text { Femoropopliteal (PTFE) + distal } \\
\text { popliteal artery (SVG) bypass }\end{array}$ & $16(19)$ \\
\hline $\begin{array}{l}\text { Proximal popliteal-tibialis anterior } \\
\text { artery (SVG) bypass }\end{array}$ & $30(36)$ \\
\hline $\begin{array}{l}\text { Proximal popliteal-tibialis posterior } \\
\text { artery (SVG) bypass }\end{array}$ & $11(13)$ \\
\hline $\begin{array}{l}\text { Proximal popliteal-distal popliteal } \\
\text { artery (SVG) bypass }\end{array}$ & $13(15)$ \\
\hline $\begin{array}{l}\text { Proximal popliteal-dorsalis pedis } \\
\text { artery (SVG) bypass }\end{array}$ & $5(6)$ \\
\hline $\begin{array}{l}\text { Proximal popliteal-posterior tibial } \\
\text { artery (SVG) bypass }\end{array}$ & $8(9)$ \\
\hline
\end{tabular}

PTFE - polytetrafluoroethylene, SVG - saphenous vein graft 
Table III. Bollinger scoring of arterial segments

\begin{tabular}{|lc|}
\hline Variable & Score $($ mean \pm SD $)$ \\
\hline Profunda femoris artery & $1.06 \pm 0.7$ \\
\hline Superficial femoral artery & $6.1 \pm 3.1$ \\
\hline Popliteal artery & $7.7 \pm 2.7$ \\
\hline Anterior tibial artery & $10.0 \pm 3.6$ \\
\hline Peroneal artery & $6.4 \pm 2.06$ \\
\hline Posterior tibial artery & $11.4 \pm 2.2$ \\
\hline
\end{tabular}

Table IV. Complications observed in long-term follow-up

\begin{tabular}{|lc|}
\hline Complication & Numbers \\
\hline Mortality & 6 \\
\hline Stroke & 1 \\
\hline MI & 3 \\
\hline \begin{tabular}{l} 
Thrombosed bypass procedures \\
\hline $\begin{array}{l}\text { Femoropopliteal-distal popliteal } \\
\text { artery bypass }\end{array}$
\end{tabular} & 2 \\
\hline $\begin{array}{l}\text { Proximal popliteal-tibialis posterior } \\
\text { artery bypass }\end{array}$ & 16 \\
\hline $\begin{array}{l}\text { Proximal popliteal-dorsalis pedis } \\
\text { artery bypass }\end{array}$ & 3 \\
\hline $\begin{array}{l}\text { Amputation } \\
\text { Major }\end{array}$ & 3 \\
\hline Minor & 3 \\
\hline Ulcer recurrence & 10 \\
\hline
\end{tabular}

\section{Results}

Short-term results of the patients were evaluated in the first 3 months of the postoperative period. Ankle-brachial index above 0.8 was maintained in $44(53 \%)$ patients, and an $A B I$ between 0.8 and 0.6 in $20(24 \%)$ patients, between 0.6 and 0.5 in 17 (20\%) patients and less than 0.5 in 2 (2\%) patients was measured. Limb salvage was possible in 44 (53\%) patients, and there was a mild increase in arterial flow in 37 patients; however, no significant flow increase occurred in 2 patients and ischemic necrosis could not be controlled in these particular cases, which resulted in major amputation. In addition, 8 minor amputations were performed in patients with $A B I$ between 0.6 and 0.5 . In the early postoperative period (postoperative day 0) 3 patients required reoperation. Reoperations were performed for graft thrombosis ( $\mathrm{n}: 2)$ and hematoma $(n: 1)$ in the distal anastomosis site. Myocardial infarction occurred in 1 patient and cardiac ischemia led to mortality in this case. Ulcer recovery was determined in 30 (36\%) patients. Despite surgical interventions and medical treatment, 6 foot ulcers remained untreated. In the 3-month post-operative period the graft patency rate was $95.1 \%$.

Mean long-term follow-up time was $17.2 \pm 7.8$ months. Complete recovery was maintained in $40(48 \%)$ patients, and there was mild improvement in $22(26 \%)$ cases. The effectiveness was $74 \%$. In the long-term follow-up the graft patency rate was $79 \%$. Graft thrombosis was seen in patients who had undergone femoropopliteal and distal popliteal artery bypass procedures ( $\mathrm{n}: 11)$, proximal popliteal artery to dorsalis pedis artery bypasses ( $n: 3)$, and proximal popliteal artery to posterior tibial artery (n:3) bypass procedures (Table IV). Endothelial hyperplasia at the distal anastomosis site, inadequate anticoagulant therapy and insufficient proximal or distal arterial runoff were determined as the causes of graft failure. Thrombectomy and new bypass procedures were performed in 10 of these patients. Debridement and medical treatment procedures were performed in 7 patients in the long term. Thirteen patients underwent various amputations (10 minor, 3 major). In total, 5 major amputations were performed and 2 of them were below the knee, 1 was Syme's amputation and 2 were mediotarsal amputation. Ulcer recurrence was observed in $6(7 \%)$ patients. In long-term follow-up 6 further mortalities occurred; 1 patient died from stroke, 3 died from myocardial infarction, and 2 died from congestive heart failure (Table IV).

\section{Discussion}

Distal arterial revascularization in patients with critical limb ischemia is a limb saving procedure. The literature includes reports of higher incidence of peripheral arterial disease and poor prognosis in the diabetic patient population [4, 5]. However, Maharaj et al. [6] reported no difference between diabetic and nondiabetic patients with respect to the lower limb graft patency, morbidity and mortality rates. In addition, favorable results have been obtained supporting distal revascularization in diabetic patients [7-9].

Ischemia of the lower limb is an important social health problem $[10,11]$. Limb salvage in patients with extensive tibial and peroneal occlusive disease is feasible with aggressive revascularization of the vessels of the ankle and foot $[12,13]$. The main goal of distal arterial revascularization procedures is to eliminate symptoms, achieve recovery of ulcers, obtain high graft patency and return the patients to an active social life [10,11].

In our study, the limb salvage rate in the longterm follow-up was $74 \%$ and graft patency was found to be $79 \%$ and the results were consistent with Maharaj et al.'s findings [6]. Poor graft patency with femoropopliteal and distal popliteal artery bypass procedures was observed. These procedures constituted $19 \%$ of all bypass procedures and were 
the cause of $62 \%$ of all graft thromboses (Table IV). The 2-year primary patency rate for above-knee femoropopliteal bypass with PTFE graft was reported as $57 \%, 55 \%$, and $54 \%$ in different series [1417]. Consequently, above-knee femoropopliteal bypasses with ePTFE grafts were not related to high patency rates. The high incidence of graft thrombosis with this procedure may be related to the quality of inflow and outflow structures [17].

Patency of bypass procedure is related to many factors such as diabetes mellitus, graft material, anastomosis site, and tobacco use. Patency rates are lower in diabetic patients; consequently reversed saphenous vein had higher patency rates than PTFE grafts. A significant difference was reported between RSV and the PTFE grafts below the knee level. However, the only factor other than graft type and distal anastomotic site that consistently correlated with late patency was tobacco use [18]. In this study anastomosis sites were all below the knee level and graft material was reversed saphenous vein for all patients. Furthermore, patency rates of bypass procedures in diabetic and/or tobacco addicted patients were low, as reported by previous studies $[10,11,19]$.

There are studies which focused on the effects of endoluminal interventions for the treatment of infrapopliteal arterial stenosis or occlusions. These interventions include angioplasty, angioplasty with stenting, subintimal angioplasty, cutting balloon angioplasty and vibrational angioplasty. However, even the short-term results of these procedures have been reported with poor outcomes when compared to the traditional standards [20-22]. Furthermore, the Bypass versus Angioplasty in Severe Ischaemia of the Leg (BASIL) trial [23] was published in 2010. This study reported that angioplasty was associated with a significantly higher early failure rate than bypass surgery, and bypass surgery with vein offered the best long-term patency. The surgical strategy we followed corresponds to these results $[3,23]$.

Additional risk factors are former amputation and recurrent ulcers, and treatment with insulin may increase the risk of amputation despite distal revascularization procedures in diabetic patients with critical limb ischemia [24]. In our study, 5 major and 18 minor amputations were performed. Unfortunately, in some circumstances, despite perfusion of the tissues, tissue necrosis may be inevitable [24, 25].

Circulatory diseases are the main causes of mortality in diabetic patients. Cardiac and cerebral disorders are the leading factors among them [26, 27]. In our study, there were 6 deaths in total. Among them, 5 were due to cardiac events and 1 was caused by stroke.

In conclusion, lower limb ischemia is a serious event in patients with diabetes mellitus. It may lead to increased mortality and morbidity in this particular patient population. However, distal arterial revascularizations are considerably effective procedures to avoid amputation, to eliminate symptoms, to promote ulcer recovery and to help the patient participate in social life with acceptable short, mid- and long-term follow-up results. However, further studies are warranted to prevent ischemic feet, improve interventional measures and achieve better graft patency rates in diabetic patients.

\section{References}

1. Hanna GP, Fujise K, Kjellgren O, et al. Intrapopliteal transcatheter interventions for limb salvage in diabetic patients: importance of aggressive interventional approach and role of transcutaneous oximetry. J Am Coll Cardiol 1997; 30: 664-9.

2. Wild S, Roglic G, Green A, Sicree R, King H. Global prevalence of diabetes: estimates for the year 2000 and projections for 2030. Diabetes Care 2004; 27: 1047-53.

3. Bollinger A, Breddin K, Hess $\mathrm{H}$, et al. Semi-quantitative assessment of lower limb atherosclerosis from routine angiographic images. Atherosclerosis 1981; 38: 339-46.

4. Faglia E, Favales F, Quarantiello A, et al. Angiographic evaluation of peripheral arterial occlusive disease and its role as a prognostic determinant for major amputation in diabetic subjects with foot ulcers. Diabetes Care 1998; 21: 625-30.

5. Jude EB, Oyibo SO, Chalmers N, Boulton AJ. Peripheral arterial disease in diabetic and nondiabetic patients: a comparison of severity and outcome. Diabetes Care 2001; 24: 1433-7.

6. Maharaj D, Ozsvath KJ, Darling RC 3rd, et al. Durability of the dorsalis pedis artery reconstruction in diabetics and nondiabetics: is there a difference? Ann Vasc Surg 2002; 16: 102-7.

7. Faries PL, Brophy D, LoGerfo FW, et al. Combined iliac angioplasty and infrainguinal revascularization surgery are effective in diabetic patients with multilevel arterial disease. Ann Vasc Surg 2001; 15: 67-72.

8. Grego F, Antonello M, Stramana R, Deriu GP, Lepidi S. Popliteal-to-distal bypass for limb salvage. Ann Vasc Surg 2004; 18: 321-8.

9. Yasa H, Cakir C, Tetik O, et al. Bypass grafting for infrapopliteal occlusive disease with poor distal flow on angiography. Anadolu Kardiyol Derg 2008; 8: 444-8.

10. Unal O, Karatepe O, Ugurlucan M, Koc B, Filizcan U, Aksoy $M$. Effects of lower extremity revascularization on the endothelial functions measured with noninvasive brachial artery flow-mediated dilatation. Ann Vasc Surg 2011; 25 : 969-74.

11. Alpagut U, Ugurlucan M, Banach M, Mikhailidis DP, Dayioglu E. Does gender influence the patency of infrainguinal bypass grafts? Angiology 2008; 59: 278-82.

12. Shah DM, Darling RC 3rd, Chang BB, Kaufman JL, Fitzgerald KM, Leather RP. Is long vein bypass from groin to ankle a durable procedure? An analysis of a ten-year experience. J Vasc Surg 1992; 15: 402-7.

13. Edwards WH, Mulherin JL. The role of graft material in femorotibial bypass grafts. Ann Surg 1980; 191: 721-6.

14. Jensen LP, Lepäntalo M, Fossdal JE, et al. Dacron or PTFE for above-knee femoropopliteal bypass: a multicenter randomised study. Eur J Vasc Endovasc Surg 2007; 34: 44-9. 
15. Allen BT, Reilly JM, Rubin BG, et al. Femoropopliteal bypass for claudication: vein vs. PTFE. Ann Vasc Surg 1996; 10 : 178-85.

16. Mamode N, Scott RN. Graft type for femoro-popliteal bypass surgery. Cochrane Database Syst Rev 1999; 2; CD001487.

17. Brown PS Jr, McCarthy WJ, Yao JS, Pearce WH. The popliteal artery as inflow for distal bypass grafting. Arch Surg 1994; 129: 596-602.

18. Rutherford RB, Jones DN, Bergentz SE, et al. Factors affecting the patency of infrainguinal bypass. J Vasc Surg 1988; 8: 236-46.

19. Aydin U, Ugurlucan M, Gungor F, et al. Effects of atorvastatin on vascular intimal hyperplasia: an experimental rodent model. Angiology 2009; 60: 370-7.

20. Ingle $H$, Nasim A, Bolia A, et al. Subintimal angioplasty of isolated infragenicular vessels in lower limb ischemia: long-term results. J Endovasc Ther 2002; 9: 411-6.

21. Ansel GM, Sample NS, Botti III CF Jr, et al. Cutting balloon angioplasty of the popliteal and infrapopliteal vessels for symptomatic limb ischemia. Catheter Cardiovasc Interv 2004; 61: 1-4.

22. Tsetis DK, Michalis LK, Rees MR, et al. Vibrational angioplasty in the treatment of chronic infrapopliteal arterial occlusions: preliminary experience. J Endovasc Ther 2002; 9: 889-95.

23. Bradbury AW, Adam DJ, Bell J, et al. Multicentre randomised controlled trial of the clinical and cost effectiveness of a bypass-surgery-first versus a balloonangioplasty-first revascularisation strategy for severe limb ischaemia due to infrainguinal disease. The Bypass versus Angioplasty in Severe Ischaemia of the Leg (BASIL) trial. Health Technol Assess 2010; 14: 1-210.

24. Adler Al, Boyko EJ, Ahroni JH, Smith DG. Lower-extremity amputation in diabetes. The independent effects of peripheral vascular disease, sensory neuropathy, and foot ulcers. Diabetes Care 1999; 22: 1029-35.

25. Toursarkissian B, Shireman PK, Schoolfield J, Blumoff RL. Outcomes following distal bypass graft occlusion in diabetics. Ann Vasc Surg 2003; 17: 670-5.

26. Araszkiewicz A, Zozulińska D, Trepińska MM, Wierusz Wysocka B. High knowledge about diabetes decreases the likelihood of retinopathy in type 1 diabetic patients treated with intensive insulin therapy from the onset of the disease. Arch Med Sci 2005; 1: 205-10.

27. Ugurlucan M, Erer D, Kalko Y, et al. Aortic stiffness in diabetes mellitus: association with glutamine and heat shock protein 70 expression: a pilot study based on an experimental rodent model. Expert Opin Ther Targets 2009; 13: 267-74. 